
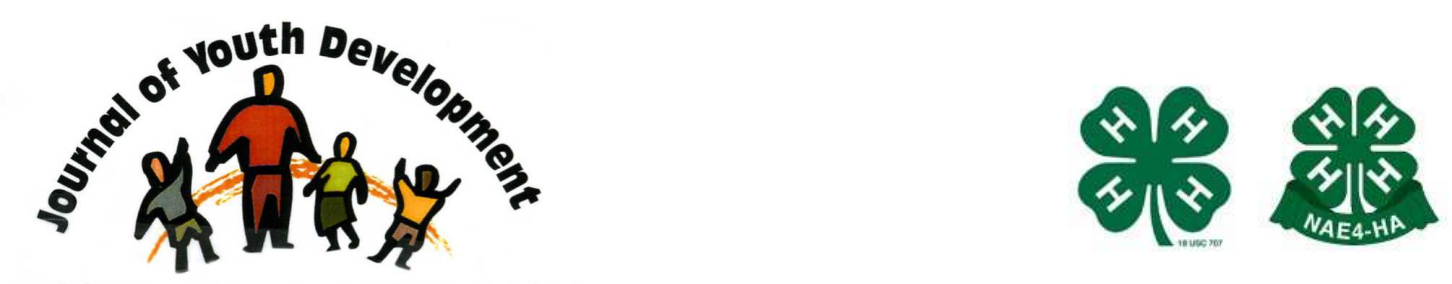

Bridging Research \& Practice

\title{
Emerging Adulthood: Theory, Assessment and Application
}

\author{
Alan Reifman \\ Human Development and Family Studies \\ Texas Tech University \\ alan.reifman@ttu.edu \\ Jeffrey Jensen Arnett \\ Clark University \\ Worcester, Massachusetts \\ Malinda J. Colwell \\ Human Development and Family Studies \\ Texas Tech University
}




\title{
JOURNAL OF YOUTH DEVELOPMENT \\ bridging research and practice

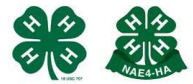

Bridging Research \& Practice

Volume 2, Number 1, Summer 2007

Article 0701FA003

\section{Emerging Adulthood: Theory, Assessment and Application}

\author{
Alan Reifman and Malinda J. Colwell \\ Texas Tech University \\ Jeffrey Jensen Arnett \\ Clark University
}

\begin{abstract}
The later attainment of traditional adult roles by today's youth compared to their counterparts of earlier decades has garnered considerable scholarly and public attention. This article describes a recent concept related to the transition to adulthood, known as emerging adulthood, including a discussion of relevant theory and historical background research. We then introduce a measurement instrument, the Inventory of the Dimensions of Emerging Adulthood (IDEA), which assesses identification with transition-to-adulthood themes. Results of initial scale-development studies were largely supportive of the measure's reliability and validity. Respondents in their 20s identified with relevant themes to a greater extent than did their younger and older counterparts. Marital status differences on the IDEA emerged, but college and noncollege respondents were largely similar. Finally, we provide suggestions for how parent educators can make use of the IDEA instrument in advising parents and their emerging adult children.
\end{abstract}

\section{Introduction}

Many markers of the transition to adulthood, such as median age of first marriage, are being reached at older ages now than in the past (Arnett, 2004a). Futhermore, large numbers of young people (sometimes referred to as "boomerang kids") are moving back in with their parents while exploring career directions, a phenomenon gaining the attention of parenting educators (Bold, 2001). In this context, the transition to adulthood has attracted great interest, both from academic researchers (Arnett, 2000; Dwyer \& Wyn, 2001; Furlong \& Cartmel, 1997) and writers for a popular audience (Karlin \& Borofsky, 2003; Robbins \& Wilner, 2001). 
Arnett $(2000,2004 a, 2004 b)$ has proposed that the time of life roughly between ages $18-25$ be considered a "distinct period" called emerging adulthood(EA). Essentially, this is a time when individuals tend to consider themselves too old to be adolescents, but not yet full-fledged adults. According to Arnett (2000):

"Having left the dependency of childhood and adolescence, and having not yet entered the enduring responsibilities that are normative in adulthood, emerging adults often explore a variety of possible life directions in love, work, and worldviews" (p. 469).

As reviewed by Arnett (2000), emerging adulthood is thought to carry its own constellation of demographic and psychological correlates.

Several other earlier theorists have proposed ideas about the developmental characteristics of a period that follows adolescence but is not fully adult. It is well known that Erikson (1968) proposed that identity is the central developmental issue of adolescence. He also commented on the "prolonged adolescence" typical of industrialized societies, and the psychosocial moratorium granted to young people in such societies, "during which the young adult through free role experimentation may find a niche in some section of his society" (p. 150).

Keniston (1970) proposed the term "youth" for a period between adolescence and young adulthood, but his ideas were based mainly on college student protesters of the late 1960s and are highly reflective of that historical time rather than of any enduring characteristics of the age period. Arnett's theory takes into account the social and demographic changes that have taken place in the decades since Erikson and Keniston proposed their theories, such as later ages of marriage and parenthood, broadened participation in higher education, and greater tolerance of premarital sexual activity and cohabitation (Arnett, 1998, 2000, 2004a).

The authors cited above who have written contemporaneously with Arnett (Dwyer \& Wyn, 2001; Furlong \& Cartmel, 1997; Karlin \& Borofsky, 2003; Robbins \& Wilner, 2001) have identified many of the same themes as he has, such as the freedom, exploration, and unpredictability of the transition to adulthood. Dwyer and Wyn, and Furlong and Cartmel, who have focused on Western nations beyond the U.S. They also go beyond Arnett in certain ways, such as consideration of public policy towards individuals in the transition to adulthood (e.g., in housing and education). Robbins and Wilner have also focused more on the psychologicaldistress aspect of this transition than have other writers. Nonetheless, these authors have all converged on a set of themes, despite coming from different countries and perspectives (i.e., academic and non-academic).

\section{Arnett's Theory}

Arnett's theory is based on research with young people who have grown up in an environment characterized by these changes, so it may reflect the experiences of young people today in a way that earlier theories do not. However, the five features of emerging adulthood proposed by Arnett (2004a, 2004b) were based on qualitative data from wide-ranging structured interviews. The present paper investigates the empirical validity of Arnett's five features of emerging adulthood by presenting a scale that was designed to investigate them and to test whether these features are more prominent during emerging adulthood than at other ages, as proposed by Arnett (2004a, 2004b). 


\section{Proposed Dimensions of Emerging Adulthood}

Arnett has continued to flesh out the dimensions of EA beyond his initial (Arnett, 2000) exposition on the topic; more recently, he has proposed that EA is characterized by five distinctive features:

- the age of identity explorations,

- the age of instability,

- the self-focused age,

- the age of feeling in-between,

- the age of possibilities (Arnett, 2004a, 2004b).

According to Arnett, emerging adulthood is the age of identity explorations because the psychosocial moratorium Erikson (1968) described is now normative and takes place in emerging adulthood. Emerging adulthood is the age of feeling in-between because the majority of emerging adults feel they are no longer adolescents but not yet fully adults (Arnett, 1998, 2001).

It is the age of possibilities because it tends to be an optimistic time of life, as a variety of potential mates, job opportunities, social causes, and other commitments are perceived by emerging adults as being available.

As emerging adults explore these possibilities, they concomitantly take on greater independence and responsibility for themselves compared to when they were younger, yet with a sense of considerable personal freedom remaining; these qualities comprise another of the dimensions, namely that of the self-focused age.

The independence, responsibility, and freedom of emerging adulthood are not complete, however. Using the example of going away to college, a common experience in emerging adulthood, students' discretion regarding their time usage, activities, and peer associations would likely be greater than when they lived at home, although many students' parents may be the ones paying the tuition. Arnett (2000) cited Goldscheider and Davanzo's (1986) term "semiautonomy" in this context. Arnett (2004a) summarizes the notion of a self-focused age in terms of how individuals "focus on themselves as they develop the knowledge, skills, and selfunderstanding they will need for adult life" (p. 14).

Whereas the four dimensions listed thus far all appear to refer in a relatively favorable light to experiences of exploring life options and "moving up" to adulthood, it is also likely that emerging adults will experience negative aspects of the transition. The sheer number of available choices and choice-points at which decisions must be made could make individuals feel overwhelmed (Robbins \& Wilner, 2001). Further, change is itself unsettling, and some individuals may lack (or feel they lack) the confidence and wherewithal to succeed. This facet of emerging adulthood refers to the age of instability.

\section{Research Topics for a Measure of Emerging Adulthood}

Some researchers have used the terms "emerging adulthood" or "emerging adults" to refer to the (roughly) 18-25 age group as a whole, much like one would use terms such as "adolescents" and "adults" to denote specific age groups (Shiner, Masten, \& Tellegen, 2002). Yet, researchers may also wish to explore individual differences in self-identification with the processes of EA, either between or within broad age groups. The present paper thus 
introduces the Inventory of the Dimensions of Emerging Adulthood (IDEA), an instrument designed to measure such individual differences. In developing the IDEA, we generated items designed to map onto the aforementioned five dimensions. An additional dimension, known as other-focus, was also developed; though not part of the primary conceptualization of EA, it represents a counterpoint to self-focus.

Initial reliability (internal consistency and test-retest) and validity information on the IDEAis presented. The latter includes comparisons on the EA dimensions by age, educational status, and role occupancy (e.g., spouse). Individuals in the roughly 18-25 age range are hypothesized to score higher on EA than individuals of other ages. Those who are attending school and those who have not yet married - and thus are exploring in the areas of career plans and/or prospective mates - are also expected to score high.

For further validity information, we examine the relationship of the EA dimensions to various psychological variables. We hypothesize that these EA dimensions (other than instability) will correlate positively with life satisfaction, self-mastery (internal control over one's life), noveltyseeking, future orientation, and imagination of possible selves. Secondly, we investigate whether young people's experience of parental control (e.g., rules) would be associated with a dampening of the exploration associated with EA or perhaps an enhancement of it as young people reacted against previous parental constraints. In addition, the EA dimensions could be used in future research to predict individuals' other behaviors, such as risky substance use or frequency of changing college majors (Arnett, 2000).

\section{Implications of Emerging Adulthood for Practice}

Bold (2001) discussed factors that could affect parents' reactions to young-adult children moving back in with them. Education of parents on the concept of emerging adulthood could give parents added understanding of their children's life choices and delays in accomplishment of traditional adult roles. Some parent educators may find it sufficient to simply present information on EA, whereas others may wish to go further and make our IDEA questionnaire available to parents to administer to their young-adult children. Parent educators, parents, and young-adult children could then discuss their answers.

\section{Method}

The methods and results of our studies are described briefly in the following sections. A longer manuscript providing greater detail in these areas is available upon request from the authors.

\section{Procedures}

All studies were based at a state university in Texas, the larger community of which is a small city located near more rural, agricultural areas. Convenience samples were used. For the studies in which we sought to compare different age groups, students in an undergraduate research methodology course administered surveys to acquaintances, friends, and family members who fell into the relevant age categories. For test-retest reliability, we administered surveys to students in the same class twice, and for the college/non-college comparison, students in a class completed surveys themselves and administered them to non-college acquaintances of theirs. These studies received human subjects approval at the host university. 


\section{Samples}

Demographics were assessed in all samples, except those used for the very brief test-retest and college/non-college studies. Females comprised $57-66 \%$ of the samples in which demographics were assessed, whereas samples were from $72.5-87 \%$ white.

\section{Measures}

The following measures were each used with one or more of the samples:

- The 31-item Inventory of the Dimensions of Emerging Adulthood (IDEA), an electronic copy of which is available at: http://www.hs.ttu.edu/hd3317/IDEA.htm.

- The brief (five-item) Satisfaction with Life Scale (Pavot \& Diener, 1993).

- An instrument measuring self-mastery (i.e., feelings of being in control of events in one's life; Marshall \& Lang, 1990; Pearlin \& Schooler, 1978).

- A modified version of Cross and Markus's (1991) measure of people's envisioned possible future selves.

- A modified version (Reifman \& Lacey, 2000) of the 12-item Consideration of Future Consequences Scale (CFC); (Strathman, Gleicher, Boninger, \& Edwards, 1994), which measures future orientation.

- The Arnett Inventory of Sensation Seeking (Arnett, 1994), which was used to measure novelty seeking.

- A measure we developed from the literature (Busby, Holman, \& Taniguchi, 2001; National Center for Education Statistics, 2001) to measure parental control, in terms of the degree to which parents made decisions for their children, had extensive rules for them, and checked on whether they were completing various tasks and requirements.

\section{Results}

Key findings, focusing on statistically significant results, are summarized briefly in three sections below: scale development and psychometrics, demographic/role comparisons, and correlations with other constructs (convergent validity).

\section{Scale Development and Psychometrics}

- Exploratory and confirmatory factor analyses largely supported the proposed fivesubscale conceptualization of emerging adulthood, plus the other-focused supplementary subscale. In two studies combined, only five item loadings smaller then .45 were obtained. Some of the subscales did exhibit large correlations $(r>.7)$ with each other, however.

- Internal consistency (alpha) reliability coefficients for the subscales were generally strong, between .70-.85. Test-retest reliability correlations (over a one-month interval) ranged from .64-.76, with the exception of the "feeling in-between" subscale (.37).

\section{Demographic/Role Comparisons}

- In comparing the age groups 18-23, 24-29, 30-39, 40-49, and 50-plus, identity exploration, experimentation/possibilities, and negativity/instability (in both samples containing these ages), and self-focus (in one sample) all were highest in the 18-23 age group and declined with older age. Other-focus (in one sample) exhibited the opposite pattern.

- In another of our studies, individuals in the purported emerging adulthood age range (college students and graduates) scored higher than did younger respondents $\left(6^{\text {th }}-12^{\text {th }}\right.$ grade) on identity exploration, other-focus, self-focus, and feeling in-between 
- Never-married individuals between 18-29 years old were compared to their age-matched engaged/married counterparts in two samples. Never-marrieds were found to be higher in identity exploration (in one sample), experimentation/possibilities (in both samples), and self-focus (in one sample), but lower in other-focus (in both samples) than the engaged-married group.

- $\quad$ Other comparisons tested EA differences among 18-29 year-olds according to employment, living arrangements, and education. The longer hours one worked, the greater the degree of other-focus and the less the feelings of experimentation. Respondents who totally paid their own expenses had the greatest sense of other-focus, whereas their counterparts who paid none of their own expenses had the least. Individuals living with friends were highest on experimentation and those with a partner/spouse lowest; individuals living with a partner/spouse scored highest on otherfocus and those in a dormitory lowest; and individuals living with friends or alone scored highest on self-focus and those living in a dormitory lowest. Identity exploration, experimentation/possibilities, and negativity/instability all increased when respondents felt that their chosen career path required greater education, whereas other-focus went down.

- We also tested for potential gender, race/ethnicity, and social class differences on the EA dimensions. Because we had no a priori predictions regarding gender differences on the IDEA, we limit our reporting to findings that replicated in more than one study. In two samples, females scored significantly higher than did males on self-focus. No significant differences were found between white and Hispanic respondents' means in any of three samples (other racial/ethnic groups had too few cases). Self-reported working class respondents scored highest on negativity/instability and uppermiddle/upper class ones lowest; the groups also differed on self-focus, with working class respondents lowest and middle and upper-middle/upper class groups at about the same, higher level.

- Only one significant difference was obtained between college students and their similarage non-college counterparts, as the former exceeded the latter on sense of experimentation/possibilities. 
Figure 1

Age-Group Differences on Identity-Exploration Subscale, in Original and Replication Studies

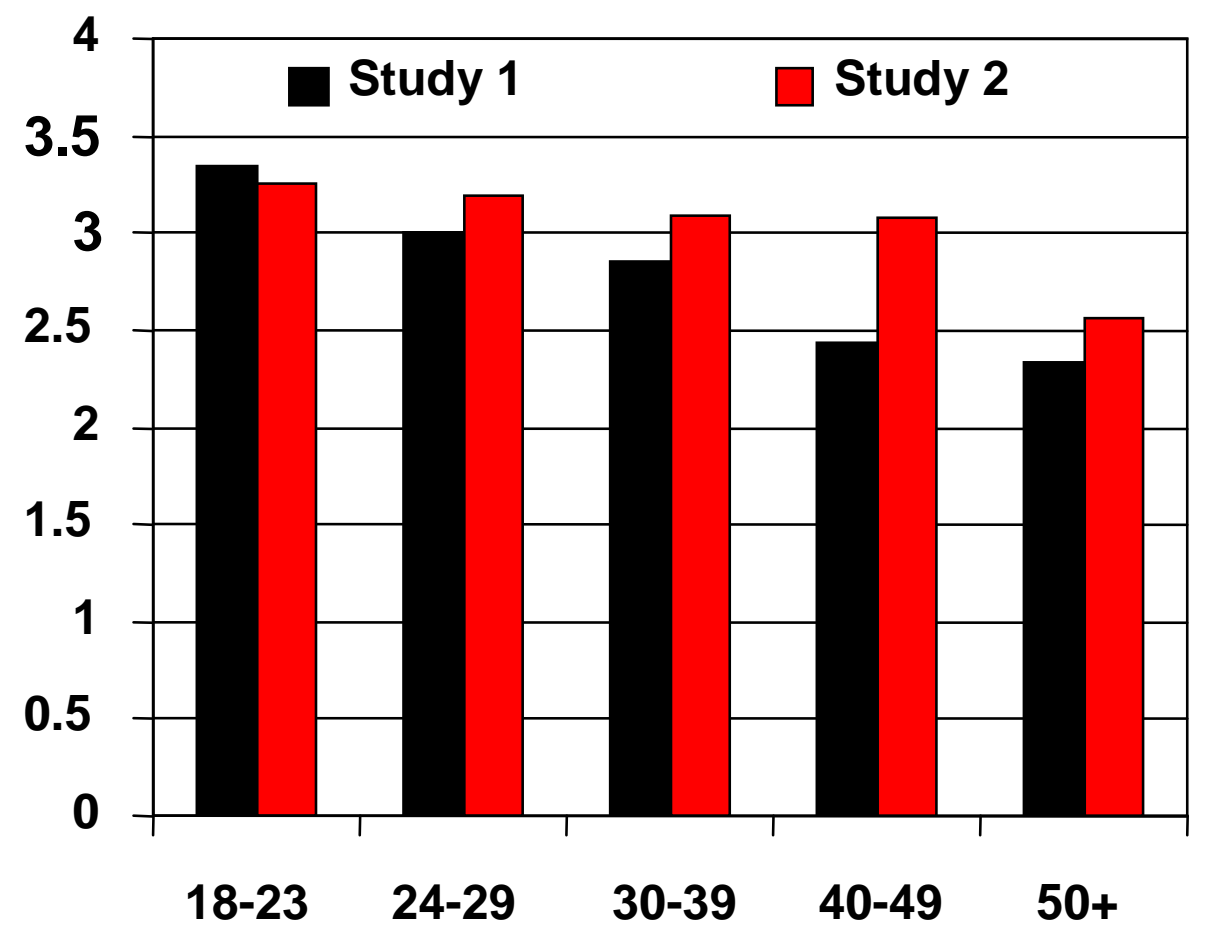


Figure 2

\section{Differences on All IDEA Subscales, in Emerging-Adult and Younger Respondents}

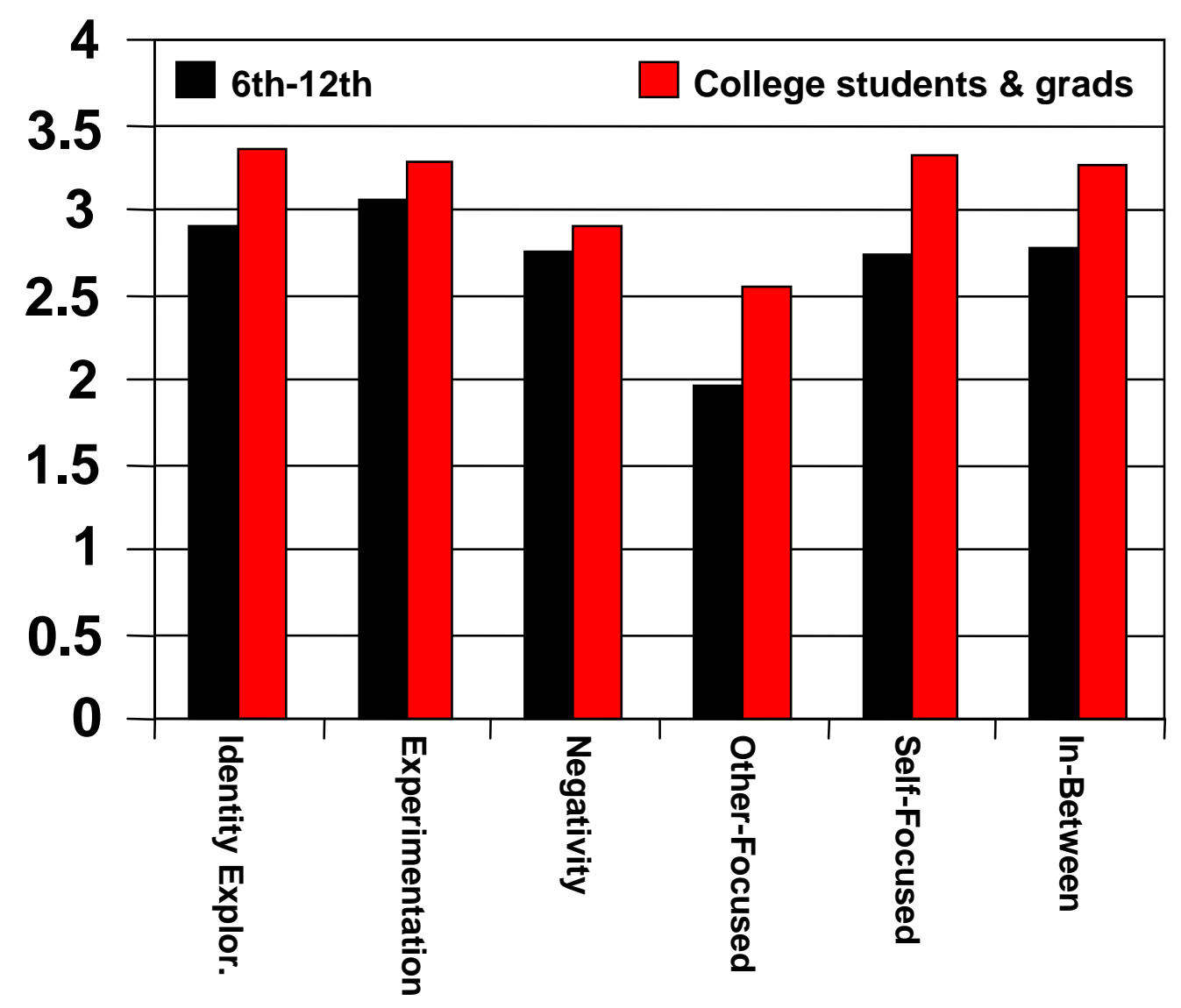

\section{Significant Correlations with Other Constructs}

- Individuals scoring highly on negativity/instability were low in life satisfaction $(r=-.38)$.

The other-focus subscale was positively related to life satisfaction $(r=.16)$.

- Individuals reporting high negativity/instability exhibited a low sense of mastery over one's life $(r=-.35)$.

- Greater self-characterization as being in an identity-exploration time of life was associated with a greater number of hoped-for possible selves $(r=.34)$, as was the perception of experiencing negativity and instability $(r=.35)$. Greater identity exploration was associated with a higher percentage of possible selves in the occupational domain $(r=.25)$, but a lower percentage in the family domain $(r=-.25)$. Greater self-focus was associated with a higher percentage of selves in the leisure domain $(r=.25)$.

- Future orientation had modest, but consistent, positive correlations with a number of IDEA subscales: identity exploration $(r=.20)$, experimentation/possibilities $(r=.22)$, other-focus $(r=.29)$, and self-focus $(r=.23)$. 
- $\quad$ None of the subscales was significantly correlated with novelty seeking.

- Higher scores on the general parental-authority subscale (i.e., greater parental assertion and less child initiative) were associated with lower identity exploration $(r=-.24)$ and self-focus $(r=-.25)$ in adolescent and college-age children. None of the subscales was correlated with the task-specific parental rules subscale.

\section{Discussion}

This paper has described the concept of emerging adulthood, provided a measure of it, and suggested how parent educators can make use of it. Initial findings appear to support Arnett's (2000) conceptualization. Most importantly, 18-29 year-olds tended to have the highest (or lowest) means on various IDEA dimensions compared to other age groups, in accordance with EA theory. Other demographic/role comparisons (e.g., marital/relationship status) also were consistent with the EA framework. The IDEA subscales also appeared to have a reasonable factor structure, generally strong reliability, and some meaningful correlations with existing constructs in the literature.

For practitioners, however, the main value of the IDEA instrument is likely to be in helping parent educators advise parents and their children who are going through the transition to adulthood. Our findings (and those of future researchers) should help normalize families' experiences of their children's transition to adulthood and enhance their understanding of the explorations being exhibited by these children. Adult children moving back home thus should not necessarily be viewed by parents as their children rebelling or "slacking." Prolonged exploration may stem from deeper reasons.

Arnett $(2000,2004 b)$ discusses several possible reasons for the later attainment of traditional adult roles such as marriage and parenthood by today's youth, compared to their counterparts of previous decades. There are structural reasons, such as greater amounts of education being required for high-technology jobs and the invention of the birth-control pill. However, Arnett (2004b) feels that the most important reason has to do with attitude and outlook:

There has been a profound change in how young people view the meaning and value of becoming an adult and entering the adult roles of spouse and parent. Young people of the 1950 s were eager to enter adulthood and "settle down. "Perhaps because they grew up during the upheavals of the Great Depression and World War II, achieving the stability of marriage, home, and children seemed like a great accomplishment to them...

The young people of today, in contrast, see adulthood and its obligations in quite a different light. In their late teens and early twenties, marriage, home, and children are seen by most of them not as achievements to be pursued but as perils to be avoided. It is not that they do not want marriage, a home, and (one or two) children-eventually. Most of them do want to take on all of these adult obligations, and most of them will have done so by the time they reach age 30. It is just that, in their late teens and early twenties, they ponder these obligations and think, "Yes, but not yet"(p. 6).

Connections between parenting and emerging adult children's exploration can be examined from additional angles, as well. Our study of adolescents and early 20 s individuals in one of our samples investigated parental control. Although correlational (and especially retrospective) data do not allow causal inference, our results suggest the possibility that parents' failure to allow autonomy to develop in their children may dampen the latter's experience of EA-relevant perceptions and sense of future orientation. Also, McCourt (2004) found that college students who scored highly on overall EA exhibited higher alcohol use/misuse and more problematic 
body-image issues and watched more television programs with thin characters than their lower EA-scoring counterparts. Thus, there could be health-related consequences of EA-related exploration.

\section{Conclusion}

In conclusion, emerging adulthood has been an active area of research for the past five years. We hope that it can also be extended to parent education and other community applications. Such applications of research findings from the IDEA instrument could include:

- Material to supplement parenting education pamphlets and informational websites for parents and emerging adults

- Career advising for emerging adults

- Information for health educators in colleges and other settings to help channel emerging adults' tendencies for exploration and experimentation into healthy, positive directions, as opposed to health-compromising risky behavior.

\section{References}

Arnett, J.J. (1994). Sensation seeking: A new conceptualization and a new scale. Personality and Individual Differences, 16 (2), 289-296.

Arnett, J.J. (1998). Learning to stand alone: The contemporary American transition to adulthood in cultural and historical context. Human Development, 41 (5-6), 295-315.

Arnett, J.J. (2000). Emerging adulthood: A theory of development from the late teens through the twenties. American Psychologist, 55 (5), 469-480.

Arnett, J.J. (2001). Conceptions of the transition to adulthood: Perspectives from adolescence through midlife. Journal of Adult Development, 8 (2), 133-143.

Arnett, J.J. (2004a). Adolescence and emerging adulthood: $A$ cultural approach (2 ${ }^{\text {nd }}$ ed.). Upper Saddle River, New Jersey: Pearson.

Arnett, J.J. (2004b). Emerging adulthood: The winding road from the late teens through the twenties. New York: Oxford University Press.

Bold, M. (2001). Boomerang Kids. On-line: http://www.unt.edu/cpe/module1/blk5boom.htm.

Busby, D.M., Holman, T.B., \& Taniguchi, N. (2001). RELATE: Relationship evaluation of the individual, family, cultural, and couple contexts. Family Relations, 50 (4), 308-316.

Cross, S., \& Markus, H. (1991). Possible selves across the life span. Human Development, 34 (4), 230-255.

Dwyer, P., \& Wyn, J. (2001). Youth, education and risk: Facing the future. London: Routledge/Falmer.

Erikson, E.H. (1968). Identity: Youth and crisis. New York: Norton. 
Furlong, A. \& Cartmel, F. (1997). Young people and social change: Individualization and risk in late modernity. Buckingham: Open University Press.

Goldscheider, F.K., \& Davanzo, J. (1986). Semiautonomy and leaving home in early adulthood. Social Forces, 65 (1), 187-201.

Karlin, J., \& Borofsky, A. (Eds.) (2003). ReGeneration: Telling stories from our twenties. New York: Tarcher/Putnam.

Keniston, K. (1970). Youth: A "new" stage of life. American Scholar, 39 (Autumn), 631-654.

Marshall, G.N., \& Lang, E.L. (1990). Optimism, self-mastery, and symptoms of depression in women professionals. Journal of Personality and Social Psychology, 59 (1), 132-139.

McCourt, A.E. (2004). Identity exploration, media usage, and health behaviors. Unpublished dissertation, Texas Tech University.

National Center for Education Statistics. (2001). National Education Longitudinal Study, 1988. Ann Arbor, MI: Inter-University Consortium for Political and Social Research.

Pavot, W., \& Diener, E. (1993). Review of the Satisfaction With Life Scale. Psychological Assessment, 5 (2), 164-172.

Pearlin L.I. \& Schooler C. (1978). The structure of coping. Journal of Health and Social Behavior, 19 (1), 2-21.

Reifman, A., \& Lacey, R.S. (2000, March-April). Age differences in propensity to consider future consequences: $A$ focus on adolescence. Paper presented at the $8^{\text {th }}$ Biennial Meeting of the Society for Research on Adolescence, Chicago.

Robbins, A. \& Wilner, A. (2001). Quarterlife crisis: The unique challenges of life in your twenties. New York: Tarcher/Putnam.

Shiner, R.L., Masten, A.S., \& Tellegen, A. (2002). A developmental perspective on personality in emerging adulthood: Childhood antecedents and concurrent adaptation. Journal of Personality and Social Psychology, 83 (5), 1165-1177.

Strathman, A., Gleicher, F., Boninger, D.S., \& Edwards, C. S. (1994). The consideration of future consequences: Weighing immediate and distant outcomes of behavior. Journal of Personality and Social Psychology, 66 (4), 742-752.

\section{Acknowledgments}

An earlier version of this manuscript was presented at the $111^{\text {th }}$ Annual Convention of the American Psychological Association, August 2003, Toronto, Canada. We would like to thank the student assistants who helped with managing the data files: Karin Doederlein, Penny Gonzalez, Tamsen Harsch, Sarah Hendley and Qingfang Song.

(C) Copyright of Journal of Youth Development Bridging Research and Practice. Content may not be copied or emailed to multiple sites or posted to a listserv without copyright holder's express written permission. However, users may print, download or email articles for individual use. 